\title{
Efficacy of Photobiomodulation Therapy for Orthodontic Pain Control Following the Placement of Elastomeric Separators: A Randomized Clinical Trial
}

\author{
AmirHossein Mirhashemi $^{1}{ }^{\mathbb{D}}$, Seyedreza Rasouli ${ }^{\mathbb{D}}$, Shiva Shahi ${ }^{*}{ }^{\mathbb{D}}$, Nasim Chiniforush $^{4,5^{*} \mathbb{D}}$ \\ ${ }^{1}$ Associate Professor, Orthodontic Department, School of Dentistry, Tehran University of Medical Sciences, International \\ Campus, Tehran, Iran \\ ${ }^{2}$ Assistant Professor, Department of Orthodontics, School of Dentistry, Shahed University of Medical Sciences, Tehran, Iran \\ ${ }^{3}$ School of Dentistry, Tehran University of Medical Sciences, International Campus, Tehran, Iran \\ ${ }^{4}$ Assistant Professor, Dental Implant Research Center, Dentistry Research Institute, Tehran University of Medical Sciences, \\ Tehran, Iran \\ ${ }^{5}$ Department of Surgical Sciences and Integrated Diagnostics, University of Genoa, Genoa, Italy
}

\author{
*Correspondence to \\ Nasim Chiniforush, \\ DDS, PhD; Assistant Professor, \\ Dental Implant Research Center, \\ Dentistry Research Institute, \\ Tehran University of Medical \\ Sciences, Tehran, Iran, Address: \\ Dentistry Research Institute, \\ Tehran University of Medical \\ Sciences, Qods Ave, Tehran, \\ Iran. \\ Tel: +989124949121; \\ Email: n-chiniforush@sina.tums. \\ ac.ir; \\ Shiva Shahi, \\ DDS; Tehran University of \\ Medical Sciences, International \\ Campus, Tehran, Iran. \\ Email: shiva_shahii@yahoo.com
}

Published online February 22, 2021

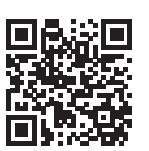

\begin{abstract}
Introduction: Controlling pain in orthodontic patients has gained special attention. This study assessed the efficacy of photobiomodulation therapy (PBMT) for pain control following the placement of elastomeric separators.

Methods: This split-mouth single-blind randomized clinical trial evaluated 30 orthodontic patients who required posterior elastomeric separators. The two maxillary quadrants were randomized into the laser and control groups. In the laser quadrant, an $808 \mathrm{~nm}$ diode laser $\left(400 \mathrm{~mW}, 15.60 \mathrm{~J} / \mathrm{cm}^{2}\right.$, 11 seconds, continuous-wave, contact mode) was irradiated to the cervical third of the maxillary first molar roots 24 hours prior to the placement of separators. The control quadrant received placebo radiation by a light-curing unit. The patients received the second laser cycle right before the placement of separators 24 hours later. The level of self-perceived pain was recorded at 0, 2, 6, 24 , and 72 hours and 5 days after the intervention in the laser and control quadrants using a visual analog scale (VAS). Data were analyzed using the analysis of variance (ANOVA) and paired-samples $t$ test.

Results: The trend of change in the pain score was similar in both groups. The pain score was significantly lower in the laser group than the control group at all-time points $(P<0.05)$ except at time 0 . The pain score increased in the first 6 hours and reached its maximum level in 24 hours in both groups.

Conclusion: PBMT by an $808 \mathrm{~nm}$ diode laser can effectively decrease pain following the placement of elastomeric separators.

Keywords: Orthodontics; Pain; Separator; Photobiomodulation therapy; Diode; Low-level laser therapy.
\end{abstract}

\section{Introduction}

Orthodontic treatment is required for some patients to enhance their masticatory function and smile esthetics. Orthodontic pain is an unwanted side effect of orthodontic treatment that causes some concerns for patients. ${ }^{1}$ Orthodontic forces cause orthodontic tooth movement and bone remodeling around the roots, which can generate pain. Evidence shows that $70 \%$ to $95 \%$ of orthodontic patients complain of pain due to orthodontic appliances. $^{2}$ Also, $8 \%$ to $30 \%$ of orthodontic patients discontinue treatment due to pain. ${ }^{1,3-7}$ Around $90 \%$ of patients experience pain in the initial stages of orthodontic treatment, which decreases their cooperation, impairs their treatment course, speech, and mastication, and can adversely affect their oral health-related quality of life. ${ }^{8}$ A high percentage of orthodontic patients complain of sleep disturbances due to pain in the first week following the placement of orthodontic archwires. ${ }^{9}$ Orthodontic pain is often described as a sense of pressure, tension, or soreness. ${ }^{10}$ The pain is continuous in the first 1-2 days and then becomes interrupted after 2 days. ${ }^{10}$

Elastomeric separators are among the most commonly used orthodontic appliances that can cause pain. ${ }^{11}$ Separators are used to create a space between the banded

Please cite this article as follows: Mirhashemi A, Rasouli S, Shahi S, Chiniforush N. Efficacy of photobiomodulation therapy for orthodontic pain control following the placement of elastomeric separators: a randomized clinical trial. J Lasers Med Sci. 2021;12:e8. doi:10.34172/ jlms.2021.08 
teeth, which is a painful procedure. ${ }^{12}$ Pain starts around 2 hours after the placement of orthodontic separators and reaches its maximum level at 24 hours. ${ }^{13}$ The pain gradually subsides from day 3 and reaches its minimum level on days 5 and $7 .^{14}$

Pain due to orthodontic treatment has an inflammatory origin. Pain with inflammatory origin is often managed by the use of non-steroidal anti-inflammatory drugs, which are the gold standard for this purpose. However, nonsteroidal anti-inflammatory drugs decelerate orthodontic tooth movement and have many contraindications. ${ }^{15}$ Also, they have systemic side effects such as allergic reactions, thrombocytopenia, skin rash, hypertension, headache, nephrotoxicity, hepatic toxicity, gastrointestinal problems, and an increase in the risk of heart disease..$^{15,16}$

Recently, photobiomodulation therapy (PBMT) formerly known as low-level laser therapy was suggested as an alternative to pharmaceutical therapy. ${ }^{17}$ Evidence shows that PBMT has no adverse systemic effects. ${ }^{18-20}$ The analgesic efficacy of PBMT in dentistry has previously been documented. ${ }^{4,21}$ A previous study demonstrated higher analgesic efficacy of PBMT than ibuprofen, infrared laser, and bite wafer. ${ }^{22}$ Another group of researchers refuted the optimal analgesic efficacy of PBMT for pain control following the placement of separators. ${ }^{23}$ Considering the existing controversy and variations in laser parameters and protocols, this topic is still in need of further investigation. ${ }^{24}$ The purpose of this study was to test the hypothesis whether an $808 \mathrm{~nm}$ diode laser can decrease orthodontic pain following the placement of elastomeric separators.

\section{Materials and Methods}

This split-mouth randomized single-blind clinical trial evaluated 30 patients (11 males and 19 females).

The minimum sample size was calculated to be 25 according to a study by Furquim et $\mathrm{al}^{25}$ assuming alpha $=0.05$, beta $=0.2$, mean visual analog scale (VAS) score difference of 1 unit between the right and left quadrants, and standard deviation of 1.7 , using paired means power analysis feature of PASS II software.

\section{Patient Selection}

The patients were selected among orthodontic patients (aged from 13 to 37 years-old) referred to a private orthodontic clinic whose treatment plan included the use of separators (Orthotechnology, USA) with $1.3 \mathrm{~mm}$ thickness. The patients were selected using randomized sampling. The patients were briefed about the study and signed informed consent forms prior to their participation. Informed consent was also obtained from the parents of patients under 18 years of age.

\section{The Inclusion Criteria}

The inclusion criteria included absence of systemic diseases, periodontal or periapical diseases, having sound maxillary first molars bilaterally with sound and firm proximal contacts, absence of a posterior open bite, completely erupted second premolars and second molars bilaterally, no history of previous orthodontic treatment, absence of severe tilting of teeth, absence of ankylosis, good oral hygiene, and willingness for participation in the study.

\section{The Exclusion Criteria}

The exclusion criteria included intake of analgesics, anti-inflammatory medications, contraceptives, antidepressants, anticonvulsants, steroids, or bisphosphonates prior to the study or during the course of the study, chronic pain, facial neuralgia, psychological disorders, several root canal treatments in the posterior region, gingival inflammation, presence of gingival pigmentation in the area, spacing between molar and premolar teeth, several missing teeth, any local or systemic condition that could affect pain perception, pregnancy or nursing, and dental or periodontal problems. Also, the patients who had dental or gingival pain prior to the treatment onset were excluded. The patients who did not completely fill out the VAS questionnaire, those who took analgesics during the course of treatment, and the patients who had discontinued the treatment were also excluded. The patients were free to quit at any time.

\section{Study Design and Random Allocation Procedure}

This study had a split-mouth design. In each patient, the maxillary right and left quadrants were randomly allocated to the laser (test) and placebo (control) groups. For the random allocation of quadrants to the test and control groups, each patient was requested to pick either 0 or 1; 0 indicated laser irradiation of the left quadrant and placebo irradiation of the right quadrant while 1 indicated laser irradiation of the right quadrant and placebo irradiation of the left quadrant.

The patients were assessed by someone other than the laser operator. Furthermore, the patients were blinded to the group allocation of their quadrants because the eyes were masked during laser irradiation. Thus, the study had a double-blind design.

\section{Intervention}

The laser quadrant received the first dose of $808 \mathrm{~nm}$ diode laser irradiation with $400 \mathrm{~mW}$ power and 15.60 $\mathrm{J} / \mathrm{cm}^{2}$ energy density 24 hours prior to the placement of separators. The laser-irradiated area had a surface area of $0.282 \mathrm{~cm}^{2}$ and the duration of radiation was 11 seconds. The laser was irradiated in a continuous wave and contact mode perpendicular to the longitudinal axis of the tooth (Figure 1). A point in the cervical third of the buccal surface of the mesial and distal roots of the maxillary first molar was irradiated in the laser quadrant. The control quadrant underwent placebo irradiation for the same duration using a light-curing unit (L600A, Westcode, 


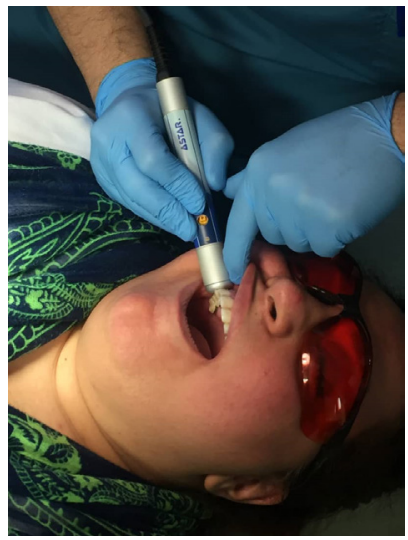

Figure 1. Laser Irradiation Prior to the Placement of Separators.

China).

The patients were visited again 24 hours after the first round of laser irradiation and received the second round of laser therapy right before the placement of separators on the maxillary first molars. The separators were then placed.

\section{Pain Assessment}

The patients were provided with a VAS questionnaire to record their self-perceived level of pain. The VAS scores ranged from 0 to $10 ; 0$ indicated no pain while 10 indicated most severe pain. The patients were requested to record their level of pain at 0, 2, 6, 24 and 72 hours and 5 days after the placement of separators for the right and left quadrants. Also, the patients were contacted at the respective time points to remind them to record their level of pain.

\section{Statistical Analysis}

Data were statistically analyzed using SPSS version 25 . The normal distribution of the data was checked by the Kolmogorov-Smirnov test. All data had normal distribution. Thus, the level of pain was compared in each group over time using repeated measures analysis of variance (ANOVA). The pain score was compared at each time point between the laser and control quadrants using a paired-samples $t$ test.

\section{Results}

Of 30 patients, 4 were excluded due to incomplete questionnaires. Thus, the data of 26 patients including 16 females and 10 males with a mean age of $20.4 \pm 5$ years (range 13 to 37 years) were statistically analyzed.

Table 1 shows the mean pain score in the laser and control quadrants at different time points. Minimum pain was noted on day 5 in the laser group (3.91) while maximum pain was noted at $24 \mathrm{~h}$ in the control group (7.92). A paired-samples t-test was applied for a pairwise comparison of the pain score between the laser and control quadrants at different time points. As shown in
Table 1, the difference in the pain score between the two groups was not significant at time $0(P=0.052)$. However, at all other time points, the pain score was significantly lower in the laser group $(P<0.05)$. The mean difference in the pain score between the laser and control quadrants was minimum at time zero (0.28) and maximum at 72 hours (0.74).

As shown in Figure 2, the pain score in the placebo group increased from time zero to 6 hours and reached its maximum level at 24 hours. At 72 hours, the pain score was almost similar to time 0 . On day 5 , the pain score was even lower than that at time 0 .

In the laser group, the trend of change in the pain score was almost similar to that in the placebo group; however, the pain score was generally lower than that in the placebo group at all time points. In both groups, the pain score at 72 hours was almost similar to that at time 0 .

\section{Discussion}

This clinical trial assessed the effect of an $808 \mathrm{~nm}$ diode laser on pain following the placement of orthodontic elastomeric separators. The results showed that PBMT decreased the severity and duration of pain.

Following the application of orthodontic forces, bone resorption is induced at the pressure site by RANK signaling in osteoclast precursors. The RANKL is specifically expressed by the osteoblasts. ${ }^{26}$ In vitro investigations have shown that the $810 \mathrm{~nm}$ laser can increase the expression of both RANKL and RANK in the tissue, which are two necessary components for the induction of tooth movement and osteoclastogenesis. Also, evidence shows that PBMT stimulates osteoblasts and induces the differentiation of osteoclasts during orthodontic tooth movement, and accelerates bone remodeling as such. ${ }^{27} \mathrm{~A}$ recent study on rats showed that irradiation of the $810 \mathrm{~nm}$ low-level laser decreased the expression of the COXII gene, and subsequently

Table 1. Mean Pain Score in the Laser and Control Quadrants at Different Time Points

\begin{tabular}{lccc}
\hline Time/Quadrant & Mean & Std. Deviation & Sig. (2-tailed) \\
\hline 0 h-(control side) & 5.66 & 2.36 & 0.052 \\
0 h-(laser side) & 5.38 & 2.40 & \\
2 h-(control side) & 6.42 & 2.21 & 0.009 \\
2 h-(laser side) & 5.80 & 2.06 & \\
6 h-(control side) & 7.27 & 1.99 & 0.03 \\
6 h-(laser side) & 6.81 & 1.99 & \\
24 h-(control side) & 7.92 & 1.85 & 0.01 \\
24 h-(laser side) & 7.22 & 1.95 & \\
72 h-(control side) & 6.36 & 1.96 & 0.00 \\
72 h-(laser side) & 5.62 & 1.86 & \\
5 days-(control side) & 4.43 & 2.30 & 0.04 \\
5 days-(laser side) & 3.91 & 2.04 & \\
\hline
\end{tabular}




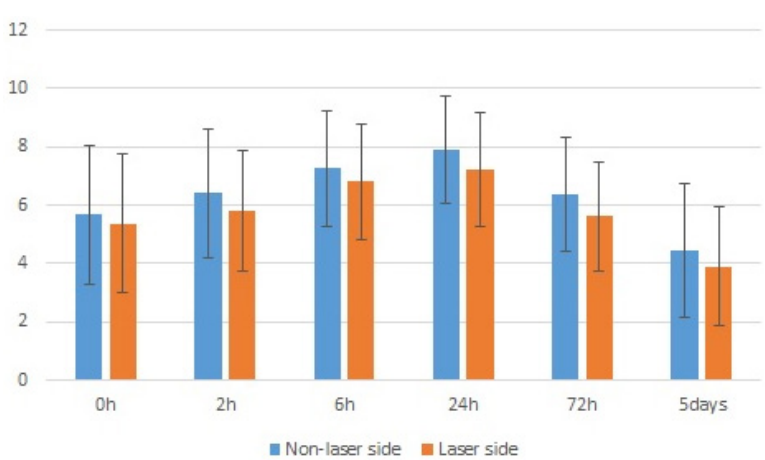

Figure 2. Error Bar of the Mean and Standard Deviation of the Pain Score at Different Time Points in the Laser and Placebo Groups .

decreased the production of prostaglandin E2 and edema, which all led to pain reduction. ${ }^{28}$ Another study showed the acceleration of tooth movement in rats by PBMT. ${ }^{29}$

The effect of lasers on orthodontic pain following the placement of archwire or canine retraction has been previously studied and all such studies have confirmed the positive efficacy of lasers for pain control. ${ }^{28-30}$ However, the level of pain following canine retraction and archwire treatments is often higher than that after separator placement, which may overestimate the effects of PBMT. Thus, it is not accurate to compare the results of such studies with this study. ${ }^{31}$

Several factors may affect the results of PBMT, such as the variability in patients' pain perception threshold, the methodology of studies, laser parameters, age and gender of patients, physiological status, previous pain experience, psychological conditions, the placebo effect, and the duration and intensity of orthodontic forces applied. ${ }^{32,33}$

This study had a split-mouth design, which is a strength of this study. This design eliminates the effect of patientrelated confounding factors on the results and better elucidates the pure effect of the intervention. ${ }^{3,34}$

The analgesic effects of PBMT are attributed to several mechanisms that increase the surface temperature and subsequently the localblood flow to the area, which induces healing. Also, by an increase in blood flow, the stimulants and the pro-inflammatory mediators are eliminated faster from the area, and cellular activity increases as such. ${ }^{7,34}$ Laser irradiation also induces the production of ATP, inhibits the release of pro-inflammatory mediators and neurotransmitters in the target tissue, and decreases pain as such. ${ }^{245}$ It induces the release of endorphins, ${ }^{4}$ stimulates lymphocytes, and directly inhibits the pain signals. ${ }^{22}$ It also inhibits the release of arachidonic acid. The effects of PBMT depend on the laser wavelength, pulse frequency, power and duration of laser irradiation. The primary effects of PBMT are related to intracellular activities such as increasing the level of ATP, redox reactions, and oxygen transfer. The secondary effects are exerted on the target tissue and include pain relief, enhanced healing, vasodilation, and decreased edema and hyperemia in inflammatory processes.

In this study, maximum pain was noted at 24 hours in both groups. Previous studies reported maximum pain at 24 and 36 hours, ${ }^{14,36} 48$ hours, ${ }^{37}$ and 6 and 30 hours. ${ }^{37}$ In this study, the pain score in both groups increased from time zero to $6 \mathrm{~h}$ and reached its maximum level at 24 hours. On day 5 , the pain score was even lower than that at time 0 . In the laser group, the pain score was generally lower than that in the placebo group at all time points. In both groups, the pain score at 72 hours was almost similar to that at time 0 . A previous study used a $\mathrm{CO}_{2}$ laser and reported no pain on day $4 .{ }^{19}$ Some other studies reported a significant reduction in pain after 24 hours. ${ }^{34,38}$ Orthodontic pain often starts within 0-2 hours after the placement of separators, ${ }^{39}$ increases within the next 6-24 hours, ${ }^{25,37}$ reaches its maximum level at 24 hours, and then decreases. ${ }^{6,11}$ It often disappears after 6-7 days. ${ }^{8}$

In this study, a VAS was used for pain assessment due to its easy use, reliability, sensitivity and reproducibility, ${ }^{40,41}$ which is commonly used in studies on pain. ${ }^{13,17}$

The diode laser was irradiated for pain relief in this study since the efficacy of the Ga-Al-As diode laser for pain relief has been previously confirmed. ${ }^{4}$ The selection of the $808 \mathrm{~nm}$ laser wavelength was due to the fact that orthodontic pain has an inflammatory origin. Thus, the selected wavelength for pain relief should exert antiinflammatory effects and has higher penetration. PBMT with an 800-830 $\mathrm{nm}$ wavelength has shown maximum analgesic efficacy. ${ }^{42}$

Controversy exists regarding the exact dose of the laser. In this study, the laser was irradiated with $15.60 \mathrm{~J} /$ $\mathrm{cm}^{2}$ energy density. The mode of laser application in a continuous or chopped mode is another controversial topic. Previous studies have reported a single dose, ${ }^{39,43}$ double dose, ${ }^{37,38}$ and multiple-dose laser irradiation. In this study, double dose laser irradiation was performed. Also, the laser was irradiated to each point for 11 seconds (a total of 22 seconds for the mesial and distal roots) since evidence shows that it is the minimum duration required for analgesic effects of laser and has minimal complications. The laser was irradiated in a continuous mode, similar to many previous studies. ${ }^{4,11}$

Our methodology in this study had some major differences with previous studies on this topic. The main difference was the irradiation of the first dose of laser 24 hours prior to the placement of separators, which decreased the severity and duration of pain in the laser quadrant at all time points.

One limitation of this study was difficulty in blinding the patients since both the laser and placebo light were irradiated in the same session. However, the eyes were masked and the patients were requested to wear dark protective glasses to ensure blinding.

Further studies are required to assess the analgesic efficacy of different laser types with different parameters. Moreover, considering the role of stress in the perceived 
pain, it would be ideal to assess the stress level of patients by the STAI-S questionnaire and exclude patients with a high level of stress to obtain more accurate results.

\section{Conclusion}

PBMT with the $808 \mathrm{~nm}$ diode laser can effectively decrease pain following the placement of orthodontic elastomeric separators.

\section{Ethical Considerations}

The study was approved by the Ethics Committee of Tehran University of Medical Sciences (IR.TUMS.DENTISTRY. REC.1397.167) and registered in the Iranian Registry of Clinical Trials (identifier: IRCT20190610043853N1).

\section{Conflict of Interests}

None.

\section{References}

1. Youssef M, Ashkar S, Hamade E, Gutknecht N, Lampert F, Mir M. The effect of low-level laser therapy during orthodontic movement: a preliminary study. Lasers Med Sci. 2008;23(1):27-33. doi: 10.1007/s10103-007-0449-7.

2. Scheurer PA, Firestone AR, Bürgin WB. Perception of pain as a result of orthodontic treatment with fixed appliances. Eur J Orthod. 1996;18(4):349-57. doi: 10.1093/ejo/18.4.349.

3. Kluemper GT, Hiser DG, Rayens MK, Jay MJ. Efficacy of a wax containing benzocaine in the relief of oral mucosal pain caused by orthodontic appliances. Am J Orthod Dentofacial Orthop. 2002;122(4):359-65. doi: 10.1067/ mod.2002.126405.

4. Doshi-Mehta G, Bhad-Patil WA. Efficacy of lowintensity laser therapy in reducing treatment time and orthodontic pain: a clinical investigation. Am J Orthod Dentofacial Orthop. 2012;141(3):289-97. doi: 10.1016/j. ajodo.2011.09.009.

5. Nóbrega C, da Silva EM, de Macedo CR. Low-level laser therapy for treatment of pain associated with orthodontic elastomeric separator placement: a placebo-controlled randomized double-blind clinical trial. Photomed Laser Surg. 2013;31(1):10-6. doi: 10.1089/pho.2012.3338.

6. Deshpande P, Patil K, Mahima VG, Shivalinga BM, Suchetha M, Ranjan A. Low-level laser therapy for alleviation of pain from fixed orthodontic appliance therapy: a randomized controlled trial. J Adv Clin Res Insights. 2016;3(2):43-6. doi: 10.15713/ins.jcri.103.

7. Bergius M, Kiliaridis S, Berggren U. Pain in orthodontics. A review and discussion of the literature. J Orofac Orthop. 2000;61(2):125-37. doi: 10.1007/BF01300354.

8. Erdinç AM, Dinçer B. Perception of pain during orthodontic treatment with fixed appliances. Eur J Orthod. 2004;26(1):79-85. doi: 10.1093/ejo/26.1.79.

9. Bondemark L, Fredriksson K, Ilros S. Separation effect and perception of pain and discomfort from two types of orthodontic separators. World J orthod. 2004;5(2):172-6.

10. Bird SB, Dickson EW. Clinically significant changes in pain along the visual analog scale. Ann Emerg Med. 2001;38(6):639-43. doi: 10.1067/mem.2001.118012.

11. Artés-Ribas M, Arnabat-Dominguez J, Puigdollers A.
Analgesic effect of a low-level laser therapy ( $830 \mathrm{~nm}$ ) in early orthodontic treatment. Lasers Med Sci. 2013;28(1):335-41. doi: 10.1007/s10103-012-1135-y.

12. Furstman L, Bernick S. Clinical considerations of the periodontium. Am J Orthod. 1972 Feb 1;61(2):138-55. doi: 10.1016/0002-9416(72)90092-9.

13. Wilson S, Ngan P, Kess B. Time course of the discomfort in young patients undergoing orthodontic treatment. Pediatr Dent. 1989;11(2):107-10.

14. Asiry MA, Albarakati SF, Al-Marwan MS, AlShammari RR. Perception of pain and discomfort from elastomeric separators in Saudi adolescents. Saudi Med J. 2014;35(5):504-7.

15. Bertolini A, Ferrari A, Ottani A, Guerzoni S, Tacchi R, Leone S. Paracetamol: new vistas of an old drug. CNS Drug Rev. 2006;12(3-4):250-75. doi: 10.1111/j.15273458.2006.00250.x.

16. Wang J, Tang X, Shen Y, Shang G, Fang L, Wang R, et al. The correlations between health-related quality of life changes and pain and anxiety in orthodontic patients in the initial stage of treatment. Biomed Res Int. 2015;2015:725913. doi: $10.1155 / 2015 / 725913$.

17. Bernhardt MK, Southard KA, Batterson KD, Logan HL, Baker KA, Jakobsen JR. The effect of preemptive and/or postoperative ibuprofen therapy for orthodontic pain. Am J Orthod Dentofacial Orthop. 2001;120(1):20-7. doi: 10.1067/ mod.2001.115616.

18. Vachiramon A, Wang WC. Acupuncture and acupressure techniques for reducing orthodontic post-adjustment pain. J Contemp Dent Pract. 2005;6(1):163-7.

19. AlSayed Hasan MMA, Sultan K, Ajaj M, Voborná I, Hamadah O. Low-level laser therapy effectiveness in reducing initial orthodontic archwire placement pain in premolars extraction cases: a single-blind, placebocontrolled, randomized clinical trial. BMC Oral Health. 2020;20(1):209. doi: 10.1186/s12903-020-01191-7.

20. Sfondrini MF, Vitale M, Pinheiro ALB, Gandini P, Sorrentino L, Iarussi UM, et al. Photobiomodulation and pain reduction in patients requiring orthodontic band application: randomized clinical trial. Biomed Res Int. 2020;2020:7460938. doi: 10.1155/2020/7460938.

21. Sobouti F, Khatami M, Chiniforush N, Rakhshan V, Shariati M. Effect of single-dose low-level helium-neon laser irradiation on orthodontic pain: a split-mouth singleblind placebo-controlled randomized clinical trial. Prog Orthod. 2015;16:32. doi: 10.1186/s40510-015-0102-0.

22. Bayani S, Rostami S, Ahrari F, Saeedipouya I. A randomized clinical trial comparing the efficacy of bite wafer and low level laser therapy in reducing pain following initial arch wire placement. Laser Ther. 2016;25(2):121-129. doi:10.5978/islsm.16-OR-10.

23. AlSayed Hasan MM, Sultan K, Hamadah O. Low-level laser therapy effectiveness in accelerating orthodontic tooth movement: a randomized controlled clinical trial. Angle Orthod. 2017;87(4):499-504. doi: 10.2319/062716-503.1.

24. Fekrazad R, Chiniforush N, Bouraima SA, Valipour M, Aslani M, Zare M, et al. Low level laser therapy in management of complications after intra oral surgeries. J Lasers Med Sci. 2012;3(4):135-40.

25. Furquim RD, Pascotto RC, Rino Neto J, Cardoso JR, Ramos AL. Low-level laser therapy effects on pain perception 
related to the use of orthodontic elastomeric separators. Dental press J Orthod. 2015;20(3):37-42. doi: 10.1590/21769451.20.3.037-042.oar.

26. Katagiri T, Takahashi N. Regulatory mechanisms of osteoblast and osteoclast differentiation. Oral Dis. 2002;8(3):147-59. doi: 10.1034/j.1601-0825.2002.01829.x.

27. Fujita S, Yamaguchi M, Utsunomiya T, Yamamoto H, Kasai K. Low-energy laser stimulates tooth movement velocity via expression of RANK and RANKL. Orthod Craniofac Res. 2008;11(3):143-55. doi: 10.1111/j.1601-6343.2008.00423.x.

28. Marcos RL, Leal Junior EC, Messias Fde M, de Carvalho $\mathrm{MH}$, Pallotta RC, Frigo L, et al. Infrared $(810 \mathrm{~nm})$ lowlevel laser therapy in rat achilles tendinitis: a consistent alternative to drugs. Photochem Photobiol. 2011;87(6):144752. doi: 10.1111/j.1751-1097.2011.00999.x.

29. Kawasaki K, Shimizu N. Effects of low-energy laser irradiation on bone remodeling during experimental tooth movement in rats. Lasers Surg Med. 2000;26(3):28291. doi: 10.1002/(sici)1096-9101(2000)26:3<282::aid$1 \mathrm{sm} 6>3.0 . \mathrm{co} ; 2-\mathrm{x}$.

30. Heravi F, Moradi A, Ahrari F. The effect of low level laser therapy on the rate of tooth movement and pain perception during canine retraction. Oral Health Dent Manag. 2014;13(2):183-8.

31. Deana NF, Zaror C, Sandoval P, Alves N. Effectiveness of low-level laser therapy in reducing orthodontic pain: a systematic review and meta-analysis. Pain Res Manag. 2017;2017:8560652. doi: 10.1155/2017/8560652.

32. Bjordal JM, Johnson MI, Iversen V, Aimbire F, LopesMartins RA. Low-level laser therapy in acute pain: a systematic review of possible mechanisms of action and clinical effects in randomized placebo-controlled trials. Photomed Laser Surg. 2006;24(2):158-68. doi: 10.1089/ pho.2006.24.158.

33. Shi Q, Yang S, Jia F, Xu J. Does low level laser therapy relieve the pain caused by the placement of the orthodontic separators? - A meta-analysis. Head Face Med. 2015;11:28. doi: 10.1186/s13005-015-0085-6.

34. Farias RD, Closs LQ, Miguens Jr SA. Evaluation of the use of low-level laser therapy in pain control in orthodontic patients: A randomized split-mouth clinical trial. Angle
Orthod. 2016;86(2):193-8. doi: 10.2319/122214-933.1.

35. Ponnudurai RN, Zbuzek VK, Wu WH. Hypoalgesic effect of laser photobiostimulation shown by rat tail flick test. Acupunct Electrother Res. 1987;12(2):93-100. doi: $10.3727 / 036012987816358896$.

36. Jones $\mathrm{M}$, Chan $\mathrm{C}$. The pain and discomfort experienced during orthodontic treatment: a randomized controlled clinical trial of two initial aligning arch wires. Am J Orthod Dentofacial Orthop. 1992;102(4):373-81. doi: 10.1016/08895406(92)70054-e.

37. Eslamian L, Borzabadi-Farahani A, Hassanzadeh-Azhiri A, Badiee MR, Fekrazad R. The effect of 810-nm low-level laser therapy on pain caused by orthodontic elastomeric separators. Lasers Med Sci. 2014;29(2):559-64. doi: 10.1007/ s10103-012-1258-1.

38. Bicakci AA, Kocoglu-Altan B, Toker H, Mutaf I, Sumer Z. Efficiency of low-level laser therapy in reducing pain induced by orthodontic forces. Photomed Laser Surg. 2012;30(8):460-5. doi: 10.1089/pho.2012.3245.

39. Esper MA, Nicolau RA, Arisawa EA. The effect of two phototherapy protocols on pain control in orthodontic procedure-a preliminary clinical study. Lasers Med Sci. 2011;26(5):657-63. doi: 10.1007/s10103-011-0938-6.

40. Erdinç AM, Dinçer B. Perception of pain during orthodontic treatment with fixed appliances. Eur J Orthod. 2004;26(1):79-85. doi: 10.1093/ejo/26.1.79.

41. Sobouti F, Rakhshan V, Chiniforush N, Khatami M. Effects of laser-assisted cosmetic smile lift gingivectomy on postoperative bleeding and pain in fixed orthodontic patients: a controlled clinical trial. Prog Orthod. 2014;15(1):66. doi: 10.1186/s40510-014-0066-5.

42. Almallah MM, Almahdi WH, Hajeer MY. Evaluation of low level laser therapy on pain perception following orthodontic elastomeric separation: a randomized controlled trial. J Clin Diagn Res. 2016;10(11):ZC23-ZC28. doi: $10.7860 /$ JCDR/2016/22813.8804

43. Farias RD, Motta RH. Low-level laser therapy for controlling pain in orthodontic patients during the use of elastic separators: randomized clinical trial. Laser Phys Lett. 2018;15(9):095602. doi: 10.1088/1612-202X/aad1c1. 